\title{
Avaliação físico-química durante a vida útil de leite UHT produzido e comercializado no Rio Grande do Sul
}

\author{
Physicochemical evaluation during shelf life of UHT millk produced and marketed in Rio Grande \\ do Sul State
}

Evaluación fisicoquímica durante la vida útil de la leche UHT producida y comercializada en Rio Grande do Sul

\author{
Jeferson Aloísio Ströher \\ ORCID: https://orcid.org/0000-0002-5314-9269 \\ Universidade Estadual do Rio Grande do Sul, Brasil \\ E-mail: jeferson.stroher@hotmail.com \\ Marta Regina dos Santos Nunes \\ ORCID: https://orcid.org/0000-0001-5339-6836 \\ Universidade Estadual do Rio Grande do Sul, Brasil \\ E-mail: marta-nunes@uergs.edu.br \\ Luís Carlos Oliveira dos Santos Junior \\ ORCID: https://orcid.org/0000-0001-5532-502X \\ Universidade Estadual do Rio Grande do Sul, Brasil \\ E-mail: luisc.oliveirajr@gmail.com
}

\begin{abstract}
Resumo
A vida útil de um produto alimentício é importante, pois define o período em que o alimento se mantém seguro em termos microbiológicos e com qualidade físico-química e sensorial adequada para o consumo. No caso do leite UHT, existem regulamentos os quais visam determinar parâmetros que denotam qualidade e segurança para produção e comercialização do produto, de maneira a evitar riscos à saúde do consumidor. Diante disto, o presente estudo teve por objetivo analisar as características físico-químicas ao longo da vida útil do leite UHT integral e desnatado de nove marcas comercializadas na região do Vale do Taquari, com sua matéria prima produzida no Estado do Rio Grande do Sul. Os experimentos foram conduzidos ao longo do prazo de validade dos produtos selecionados (180 dias), sendo realizadas a avaliações físico-químicas nos intervalos dos dias $0,45,90,120,150$ e 180 para pH, acidez titulável, estabilidade, densidade, teor de gordura, índice crioscópico e extrato seco desengordurado (ESD). Os resultados foram avaliados estatisticamente e as amostras apresentaram, em geral, um decréscimo nos seus parâmetros, exceto acidez, que apresentou uma elevação à medida que aumentava o tempo de armazenamento. Tais resultados permitiram observar que algumas marcas de leite apresentaram inconformidades com a legislação brasileira desde o início das análises, o que permitiu concluir que a matéria prima processada pode ser considerada de baixa qualidade.
\end{abstract}

Palavras-chave: Leite UHT; Vida útil; Parâmetros físico-químicos.

\begin{abstract}
The shelf life of food is important because it defines the period in which the food remains safe microbiologically and physicochemical and sensory quality suitable for consumption. In case of UHT milk, there are regulations that aim to determine parameters that denote quality and safety for processing and commercialization of the product, in order to avoid risks to the consumer's health. Therefore, the present study aimed to analyze the physicochemical characteristics over the shelf life of whole and skimmed UHT milk from nine brands marketed in the Vale do Taquari region, since its raw material produced in the state of Rio Grande do Sul. The experiments were carried out along the shelf life period of products (180 days), and physicochemical evaluations were carried out on the intervals of days $0,45,90$, 120,150 and 180 for $\mathrm{pH}$, titratable acidity, stability, density, fat content, cryoscopic index and defatted dry extract (ESD). The results were statistically evaluated, and the samples showed, in general, a decrease in their parameters, except for acidity, which showed an increase as the storage time increased. These results allowed us to observe that some milk brands have presented non-conformities with the Brazilian legislation since the beginning of the analyzes, leading us to conclude that the raw material processed can be considered of low quality.
\end{abstract}

Keywords: UHT milk; Quality; Shelf life; Physicochemical parameters. 


\begin{abstract}
Resumen
La vida útil de un producto alimentario es importante porque define el periodo en el que el alimento permanece seguro en términos microbiológicos y con una calidad fisicoquímica y sensorial adecuada para el consumo. En el caso de la leche UHT, existe una normativa que pretende determinar los parámetros que denotan calidad y seguridad para la producción y comercialización del producto, con el fin de evitar riesgos para la salud del consumidor. Teniendo en cuenta esto, el presente estudio tuvo como objetivo analizar las características físico-químicas a lo largo de la vida útil de la leche UHT entera y descremada de nueve marcas comercializadas en la región del Valle de Taquari, con su materia prima producida en el Estado de Rio Grande do Sul. Los experimentos se realizaron a lo largo de la vida útil de los productos seleccionados (180 días), realizándose las evaluaciones físico-químicas en los intervalos de los días 0, 45, 90, 120, 150 y 180 para el $\mathrm{pH}$, la acidez titulable, la estabilidad, la densidad, el contenido de grasa, el índice crioscópico y el extracto seco desgrasado (ESD). Los resultados se evaluaron estadísticamente y las muestras mostraron, en general, una disminución de sus parámetros, excepto la acidez, que mostró un aumento a medida que aumentaba el tiempo de almacenamiento. Tales resultados permitieron observar que algunas marcas de leche presentaban inconformidades con la legislación brasileña desde el inicio de los análisis, lo que permitió concluir que la materia prima procesada puede ser considerada de baja calidad.
\end{abstract}

Palabras clave: Leche UHT; Vida útil; Parámetros físico-químicos.

\title{
1. Introdução
}

O leite é considerado um alimento de alto poder nutritivo, tendo em média na sua composição cerca de $87 \%$ de água e 13\% de componentes sólidos, incluindo vitaminas (A, B, C, D e E), proteínas, minerais, lipídios e carboidratos (Pereira, 2014). Para ser consumido sem causar riscos à saúde pública, os tratamentos térmicos no leite como pasteurização e ultra alta temperatura (UHT) são essenciais para garantir a qualidade do produto e inocuidade, além de manter as características sensoriais e nutricionais inalteradas (Brasil, 2017).

O leite processado através do sistema UHT é a forma mais segura de consumo deste produto, pois elimina o risco de contaminação microbiológica por patógenos e prolonga a vida útil do alimento (o leite). O processo térmico UHT ocorre entre $130^{\circ} \mathrm{C}$ e $150^{\circ} \mathrm{C}$, por 2 a 4 segundos, em fluxo contínuo e em seguida, é imediatamente resfriado a uma temperatura inferior a $32^{\circ} \mathrm{C}$, sendo envasado sob condições assépticas em embalagens estéreis e hermeticamente fechadas (Brasil, 2017).

De acordo com a Organização das Nações Unidas para Alimentação e Agricultura (FAO), a vida útil de um alimento se define como o período em que o alimento se mantém seguro e adequado para o consumo humano, desde que siga os critérios de armazenagem e manuseio adequados. No Brasil, a Agência Nacional de Vigilância Sanitária (ANVISA), expõe que o fabricante pode determinar o prazo de validade do leite UHT produzido, sendo responsável pelo produto durante todo este período (Brasil, 1984; Codex Alimentarius, 2004; Rodrigues, et al., 2016).

Para o leite UHT ser considerado adequado para consumo humano é importante avaliar parâmetros físico-químicos e microbiológicos que determinam, entre outros fatores, a qualidade do produto. Caso tais requisitos não sejam alcançados, podem ocorrem fraudes no leite com a finalidade de obter características originais e lucratividade na sua comercialização (Carvalho, et al., 2007). As propriedades físico-químicas do leite UHT podem sofrer alterações ao longo da estocagem, incluindo pH, densidade, índice crioscópico (ponto de congelamento), acidez, ponto de ebulição, calor específico, tensão superficial, viscosidade, condutividade elétrica, sabor, odor e cor (Silva, et al., 1997; Prata, 2001; Tronco, 2008). A legislação brasileira determina inúmeras análises para o controle de qualidade do leite, tanto da matéria prima quanto do produto processado, através do Regulamento Técnico de Identidade e Qualidade (RTIQ) (Brasil, 2017).

Dentre as alterações que podem ocorrer ao longo da estocagem do leite UHT, estão: a estabilidade que é observada pela capacidade que o leite tem de suportar o efeito do calor sem a formação de grumos; a crioscopia (índice crioscópico), que verifica adulterações do leite através do ponto de congelamento. Também pode ocorrer mudanças na conformação e dispersão da gordura do leite, apercebida pela análise de densidade relativa, do teor de gordura e do extrato seco desengordurado (Singh, 2004). Além destes parâmetros, o pH e a acidez titulável também tendem a alterar ao longo do armazenamento, desde o processamento, afinal, elevadas temperaturas acarretam maior dissociação de íons no meio que podem se prolongar durante a 
estocagem do leite (Brito, et al., 2004).

Em função dos fatores citados responsáveis pela qualidade do leite UHT produzido e consumido, o objetivo deste trabalho foi avaliar os parâmetros físico-químicos do leite UHT integral e desnatado de nove (9) marcas comercializadas em estabelecimentos no Vale do Taquari, ao longo de 180 dias de armazenamento, sendo a matéria prima totalmente produzida no Estado do Rio Grande do Sul.

\section{Metodologia}

A pesquisa se caracteriza por seguir protocolos que a caracterizam como quantitativa, uma que inicia-se pela coleta de amostra, escolha e utilização de metodologias consolidadas de análise e posterior tratamento estatístico dos resultados para discussão das hipóteses elencadas (Pereira, et al., 2018). Os dados gerados foram resultantes da aplicação de diversas análises físico-químicas realizadas em 9 marcas selecionadas de diferentes indústrias de leite produzido no Estado do Rio Grande do Sul, comercializados em estabelecimentos comerciais de quatro municípios do Vale do Taquari, região central do mesmo estado. Cada marca produz leite UHT e acondiciona em embalagem cartonada do tipo "Tetra pak ${ }^{\circledR}$ contendo 1 L de produto". Foram coletados dois tipos de leite UHT de cada marca, um integral e um desnatado, totalizando 18 amostras adquiridas em até 15 dias, a partir da data de fabricação).

As amostras foram devidamente codificadas de 1 a 9, sendo acrescentadas as letras I e D para atribuir os códigos 1I a 9I, para as amostras de leite integral, e 1D a 9D, para as amostras de leite desnatado.

As análises foram realizadas no dia da coleta, identificados como dia 0 e, 45, 90, 120, 150 e 180 dias após a data de fabricação do leite UHT, totalizando 324 litros. As amostras de leite UHT utilizadas foram armazenados em local adequado, ao abrigo do sol e do calor, em temperatura ambiente $\left(25^{\circ} \mathrm{C}\right)$, reproduzindo as condições de estoque dos estabelecimentos comerciais. Os experimentos foram realizados no Laboratório de Físico-química de uma indústria de laticínios local, de acordo com as metodologias descritas pela Instrução Normativa $n^{\circ} 68$ (Brasil, 2006). Os resultados obtidos foram comparados com os padrões preconizados pelo RTIQ do leite UHT do Ministério da Agricultura, Pecuária e Abastecimento (MAPA) (Brasil, 1997) e pelo Manual de Métodos Oficiais para Análise de Alimentos de Origem Animal (Brasil, 2019). As análises físico-químicas realizadas foram: estabilidade ao álcool $68^{\circ} \mathrm{GL}$, acidez titulável $(\mathrm{g} / 100 \mathrm{~mL})$, densidade a $15{ }^{\circ} \mathrm{C}$, teor de gordura, índice crioscópico, extrato seco desengordurado (ESD) e pH, conforme legislação (Brasil, 2018).

Cada análise foi realizada em triplicata e os resultados foram avaliados estatisticamente, utilizando o programa Statistica ${ }^{\circledR}$ versão 7.0 (Statsoft, 2004), sendo que para cada marca de leite UHT foram calculadas as médias \pm desvio padrão e comparadas entre elas pelo teste de Tukey, com intervalo de confiança de $95 \%$ ( $\leq \leq 0,05)$.

\section{Resultados e Discussão}

De acordo com o Decreto $n^{\circ}$ 9.013/2017, para que o leite beneficiado seja exposto ao consumo como padronizado, semidesnatado ou desnatado, deve satisfazer as exigências do leite normal, com exceção dos teores de gordura, de sólidos não gordurosos e de sólidos totais, que devem atender ao RTIQ. O RTIQ do leite UHT (Brasil, 1997) não estabelece padrões físicoquímicos de densidade e índice crioscópico para o leite UHT. No entanto, o Decreto n ${ }^{\circ}$ 9.013/2017 que regulamenta a Lei ${ }^{\circ}$ 1.283, de 1950 e a Lei $n^{\circ} 7.889$ de 1989 , que dispõem sobre a inspeção industrial e sanitária de produtos de origem animal (Brasil, 2017), estabelece padrões para a crioscopia (índice crioscópico) (entre $-0,530^{\circ} \mathrm{H} \mathrm{e}-0,555^{\circ} \mathrm{H}$ ), e densidade relativa a $15^{\circ} \mathrm{C}$ (entre 1,028 e 1,034, expressa em $\mathrm{g} / \mathrm{mL}$ ) discutidos na sequência. Já a Instrução Normativa $\mathrm{n}^{\circ} 76$ (Brasil, 2018), que regulamenta o RTIQ do leite cru refrigerado, explana que o leite cru desnatado ou semidesnatado deve possuir a sua densidade entre 1,028 a $1,036 \mathrm{~g} / \mathrm{mL}$, porém, a referida regulamentação não explana sobre o leite UHT. Os resultados a seguir foram 
analisados, estatisticamente, e foram observadas as médias comparadas pelo teste de Tukey, onde as letras diferentes em cada marca analisada para cada parâmetro, representam a diferença significativa entre as amostras (Figs. 1 - 11).

\subsection{Análise de pH}

Os resultados para a análise de pH dos leites UHT integral (Figura 1) e desnatado (Figura 2) durante o tempo de estocagem, mostram que o comportamento das amostras foi similar $(\mathrm{p}<0,05)$ entre todas as marcas de leite analisadas e decresceram durante os 180 dias de armazenamento. A legislação não estabelece padrão para análise de pH, portanto, neste trabalho foi utilizado como parâmetro o valor estipulado pela literatura (Walstra, et al., 2006) que relata valores ideais de 6,60 e 6,80. Alguns autores, como Oliveira e Nunes (2003), relatam que para ser considerado normal, o pH do leite deve ser entre 6,6 a 6,75 .

Figura 1 - Resultados de $\mathrm{pH}$ para leite integral $\left(\mathrm{a} 25^{\circ} \mathrm{C}\right){ }^{*}$

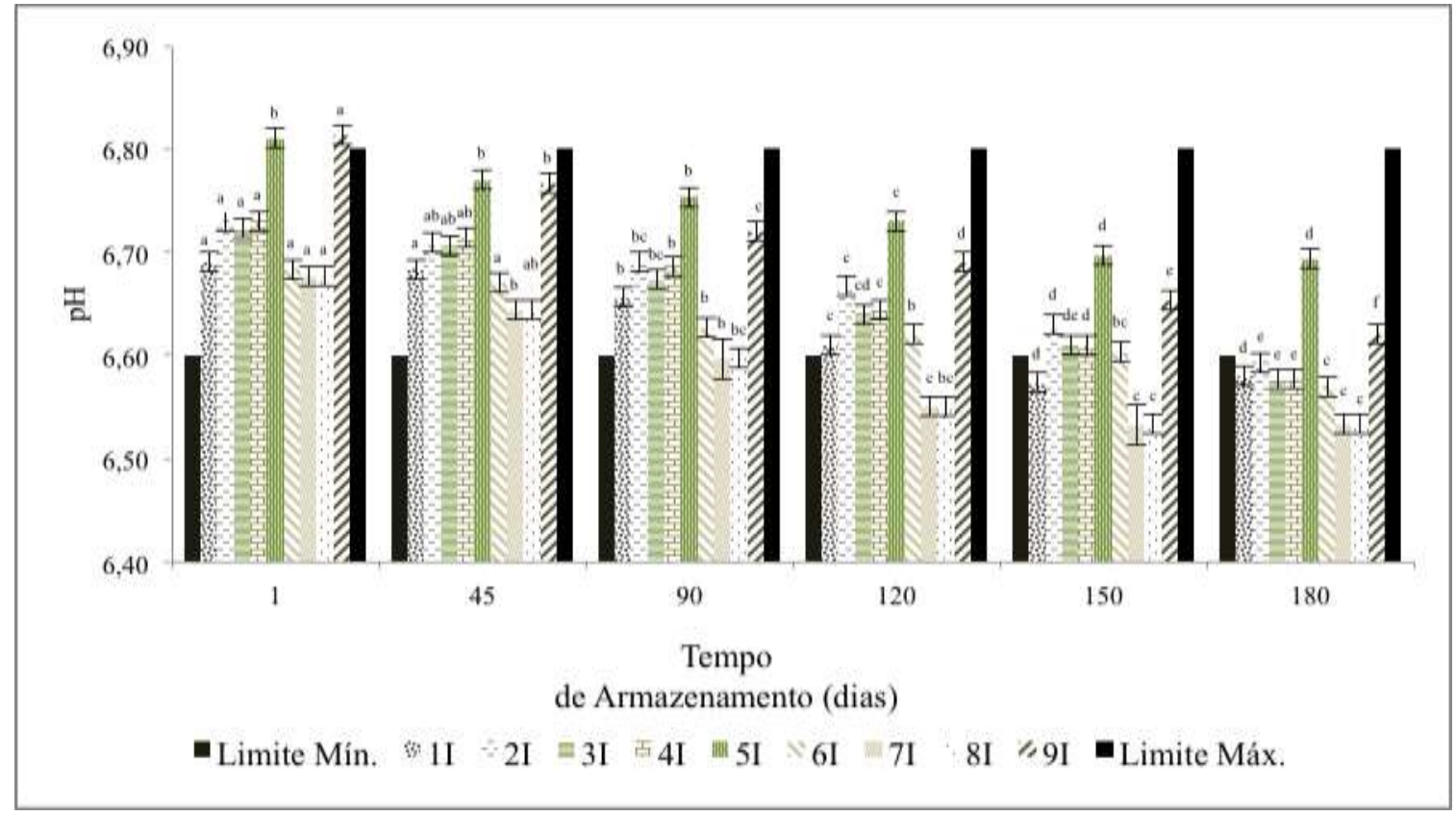

*Considerando seu limite mínimo e limite máximo representados em 6,60 e 6,80 respectivamente, de acordo com Walstra et al. (2006). Cada barra, no intervalo do tempo de armazenamento, está distribuída ordenadamente entre limite mínimo - marca 1I à marca 9I - limite máximo.

Fonte: Autores (2021). 
Figura 2 - Resultados de $\mathrm{pH}$ para leite desnatado $\left(\mathrm{a} 25^{\circ} \mathrm{C}\right){ }^{*}$

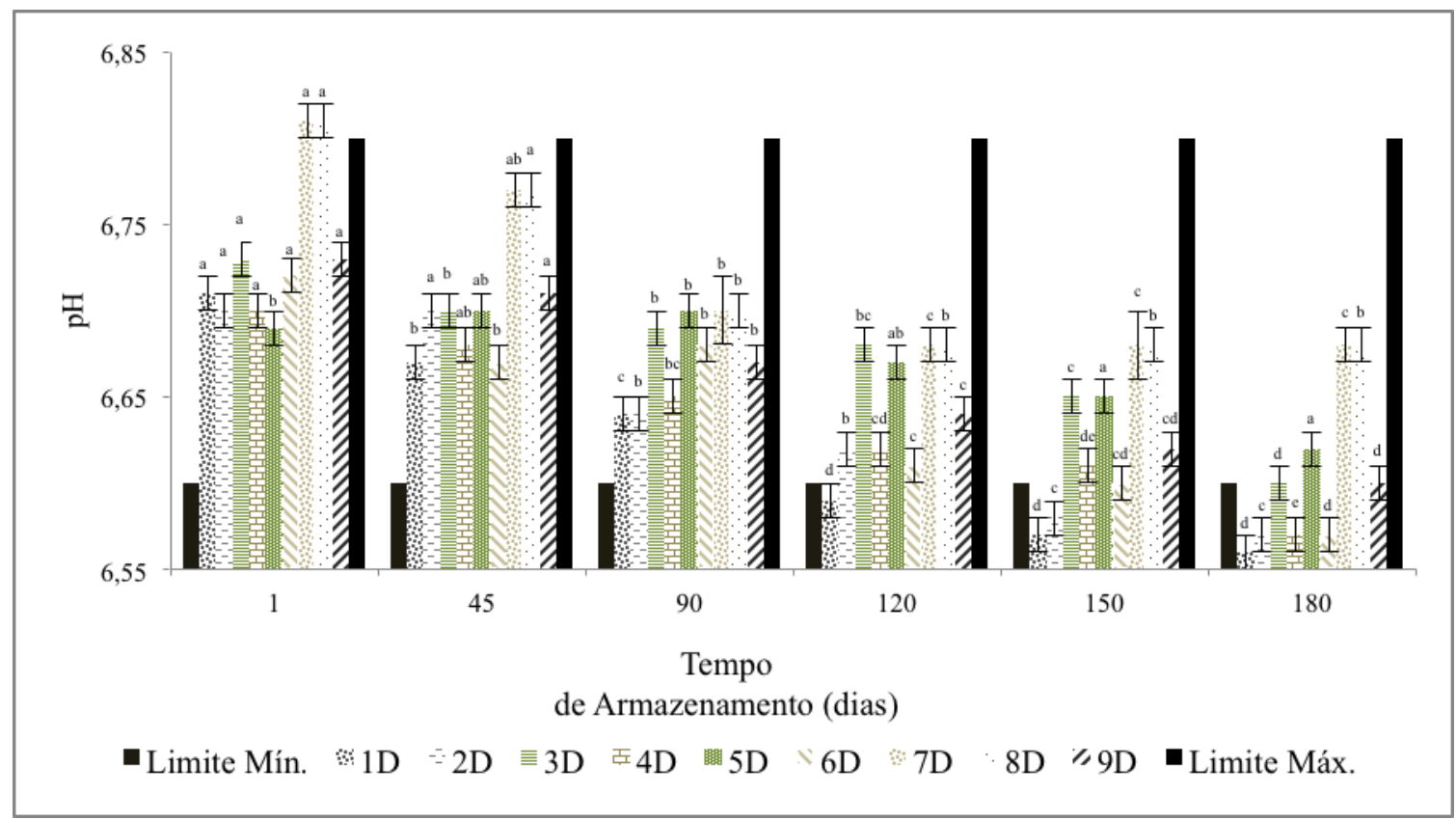

*Considerando seu limite mínimo e limite máximo representados em 6,60 e 6,80 respectivamente, de acordo com Walstra et al. (2006). Cada barra, no intervalo do tempo de armazenamento, está distribuída ordenadamente entre limite mínimo - marca 1D à marca 9D - limite máximo.

Fonte: Autores (2021).

A tendência observada para $\mathrm{pH}$, em todas as marcas, foi o decréscimo ao longo do tempo de estocagem. Em alguns casos, no dia 180, o pH decresceu para valores abaixo do limite mínimo referenciado por Walstra et al. (2006) onde os autores verificaram que o 0menor valor de $\mathrm{pH}$ encontrado no referido experimento foi de 6,53. Para Lewis \& Heppel (2000) e Bylund (1995), o decréscimo de 0,15 unidades no pH é capaz de causar sedimentação no leite e aumentar a gordura junto aos sedimentos, devido à dissociação do cálcio iônico e a solubilidade deste em leite ácido. Segundo Brito et al. (2004), em temperaturas altas, o pH do leite tende a ser muito menor em consequência da maior dissociação da água, da precipitação de fosfato tricálcico e da produção de ácido.

Três marcas de leite integral e uma de leite desnatado já apresentavam no dia 0 o pH acima do estipulado pelos autores $(6,81)$. $\mathrm{O}$ pH elevado no dia 0 pode estar relacionado à adição de fosfatos e citrato em quantidades elevadas, pois estes reagem com o cálcio, diminuindo as concentrações de cálcio iônico e de fosfato de cálcio na fase aquosa, provocando este aumento.

A variação de $\mathrm{pH}$ durante o armazenamento do leite UHT, principalmente na redução deste parâmetro ao longo da vida útil, pode ocorrer devido os ácidos formados nas reações de Maillard, à desfosforilação de caseínas, degradação da lactose e reações proteína-proteína que possuem efeito na liberação de íons $\mathrm{H}^{+}$(Al-Saadi \& Deeth, 2008; Real, et al., 2013).

\subsection{Acidez Titulável}

Os resultados para as análises de acidez titulável durante o tempo de estocagem (Figuras 3 e 4), mostram que o comportamento das amostras foi similar $(\mathrm{p}<0,05)$, sendo que houve um crescimento no teor de ácidos tituláveis em todas as marcas durante o armazenamento. 
Figura 3 - Resultados de Acidez titulável (g/100 mL) para leite integral considerando os limites mínimo e máximo de 0,14 $0,18 \mathrm{~g} / 100 \mathrm{~mL}^{*}$

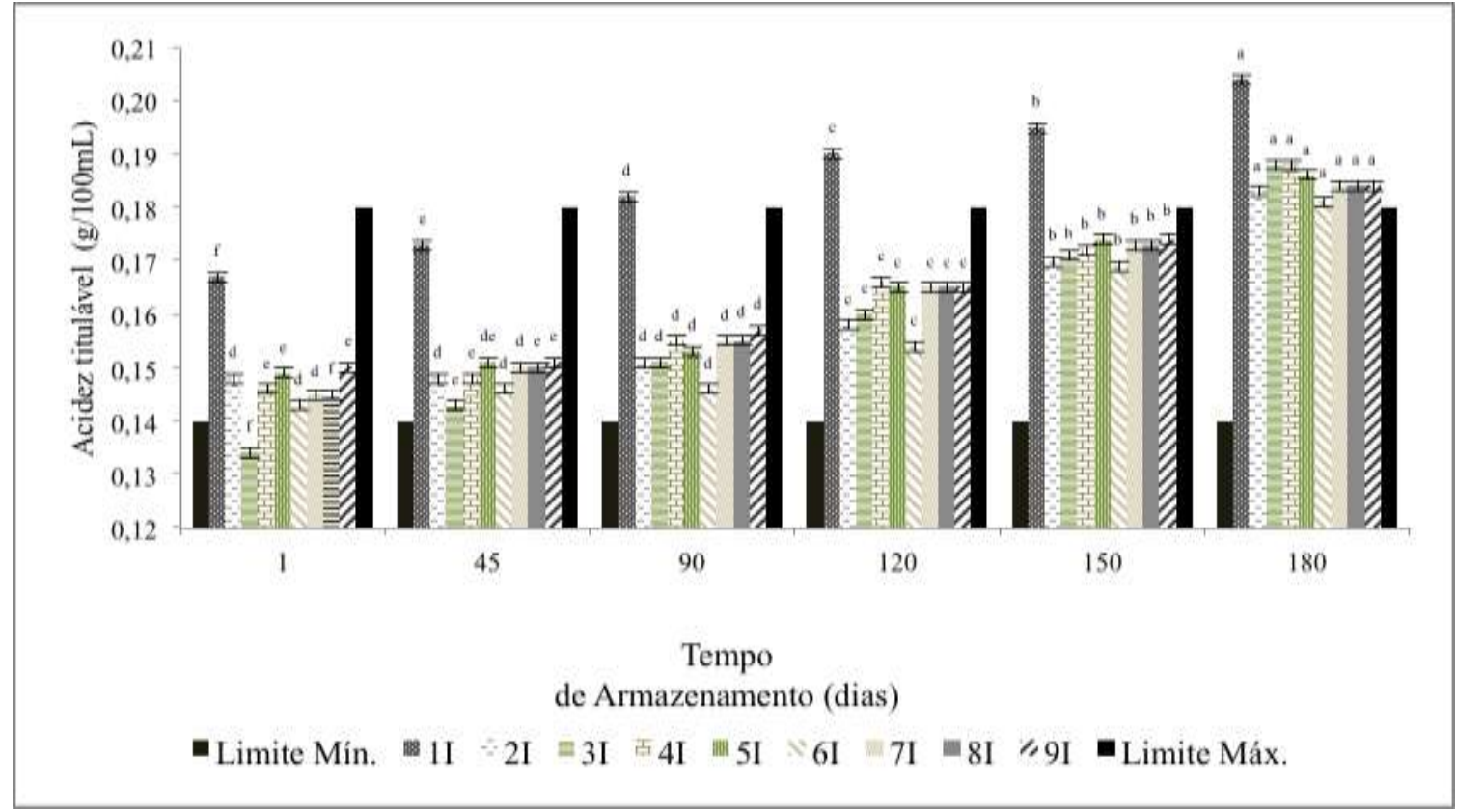

*De acordo com o Manual de Métodos Oficiais para Análise de Alimentos de Origem Animal (Brasil, 2017). Cada barra, no intervalo do tempo de armazenamento, está distribuída ordenadamente entre limite mínimo - marca 1I à marca 9I - limite máximo. Fonte: Autores (2021).

Figura 4 - Resultados de Acidez titulável (g/100 mL) para leite desnatado considerando os limites mínimo e máximo de 0,14 $0,18 \mathrm{~g} / 100 \mathrm{~mL}^{*}$

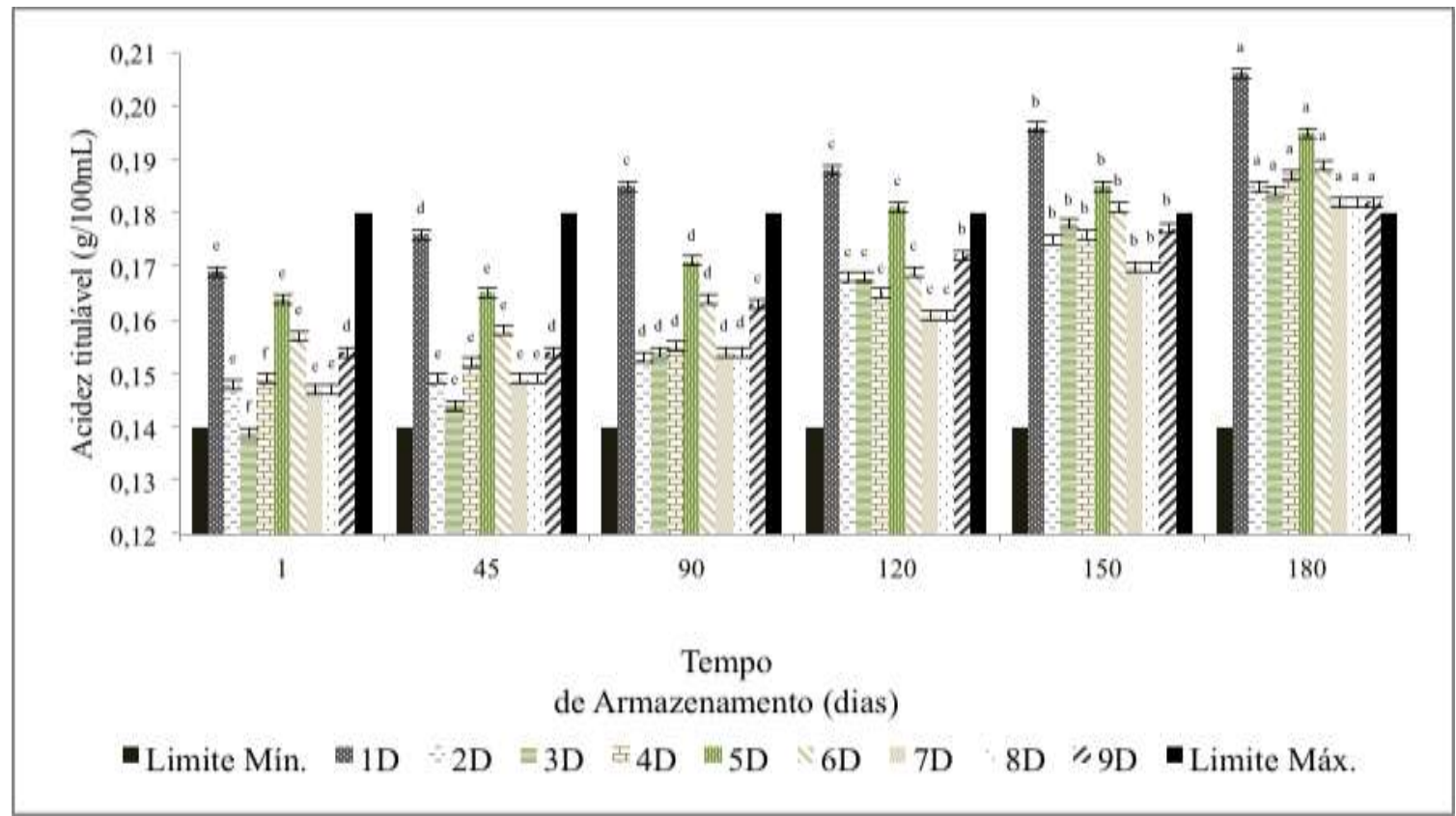

*De acordo com o Manual de Métodos Oficiais para Análise de Alimentos de Origem Animal (Brasil, 2017). Cada barra, no intervalo do tempo de armazenamento, está distribuída ordenadamente entre limite mínimo - marca 1D à marca 9D - limite máximo.

Fonte: Autores (2021).

A acidez titulável em uma das marcas, na versão desnatada, não estava dentro dos valores de referência no dia $0(0,13$ g/100 mL). Tal resultado foi semelhante a Bersot et al. (2010), que observou três amostras abaixo do limite mínimo de acidez 
em leites UHT, variando entre 0,11 a $0,13 \%$ de ácido lático. O autor atribuiu a este problema um indicativo de fraude, pois foram adicionados agentes alcalinos para a neutralização da acidez titulável.

Uma das marcas analisadas já apresentou valores mais elevados que o limite máximo no dia 90 de armazenamento. No último dia de experimento, todas as marcas analisadas apresentaram acidez titulável no limite máximo ou acima do estipulado pela legislação brasileira ( $\geq 18 \mathrm{~g} / 100 \mathrm{~mL}$ ) (Brasil, 1997; Brasil, 2017). Este teste detecta o aumento na concentração de ácido lático pela ação das bactérias mesófilas quando fermentam a lactose, indicando uma matéria prima inadequada quando a acidez titulável for superior a 0,18 g/100mL (Bhemer, 1999; Prata, 2001). Valores de acidez titulável dentro dos padrões da legislação demonstram que o leite possui baixa contagem de mesófilos e que foi armazenado sob a refrigeração adequada.

Diversos trabalhos na literatura relatam alterações na acidez titulável de leite UHT, como Katsuda et al. (2009) que avaliaram a composição físico-química de diversas marcas e verificaram que a acidez titulável estava abaixo do limite estabelecido pela legislação em $20 \%$ das amostras, porém os autores detectaram fraude nos produtos. Andrioli et al. (2001) analisaram 50 amostras de leite UHT e encontraram em doze amostras, valores acima do permitido pela legislação (Brasil, 1997; Brasil, 2017).

Martins et al. (2008) analisaram 150 amostras, a cada dois meses, em seis etapas diferentes do processamento e todos os resultados obtidos estavam dentro dos padrões estabelecidos pela legislação, assim como Bersot et al. (2010), Souza et al. (2010), Tamanini et al. (2011), Domareski et al. (2010) e Robim (2011).

\subsection{Estabilidade ao Etanol 68 (v/v)}

A estabilidade ao etanol $85^{\circ} \mathrm{GL}$ no dia 0 se manteve constante, ao longo do período do experimento, ou seja, dentro do padrão da legislação (Brasil, 1997; Brasil, 2017) em todas as marcas analisadas, com exceção de uma que apresentou decréscimo a partir do dia 120 , resultando $72^{\circ} \mathrm{GL}$ no dia 180 para o leite integral e $73^{\circ} \mathrm{GL}$ para o leite desnatado.

O teste para verificação da estabilidade ao álcool $68^{\circ} \mathrm{GL}$ é rápido e empregado para verificação da resistência do leite ao tratamento térmico. A estabilidade da fração proteica do leite diminui com o aumento da acidez, portanto, a coagulação pode ocorrer por efeito de acidez elevada ou desequilíbrio salino, quando é determinada a desestabilização das micelas pelo álcool (Tronco, 2003). Luiz et al. (2010) ao analisarem lotes de leite UHT do Brasil, Paraguai e Argentina, observaram instabilidade ao álcool a $68 \%$ apenas nos produtos brasileiros, sendo em concentrações de $72 \%, 76 \%$ e $80 \%$.

\subsection{Densidade relativa $\left(\mathrm{a}^{\circ} 5^{\circ} \mathrm{C}\right)$}

Os resultados para as análises de Densidade a $15{ }^{\circ} \mathrm{C}$ deste trabalho mostraram que o comportamento foi similar $(\mathrm{p}<0,05)$ entre todas as marcas analisadas e decresceram durante os 180 dias de armazenamento (Figuras 5 e 6 ). 
Figura 5 - Densidade a $15^{\circ} \mathrm{C}$ para leite UHT desnatado*

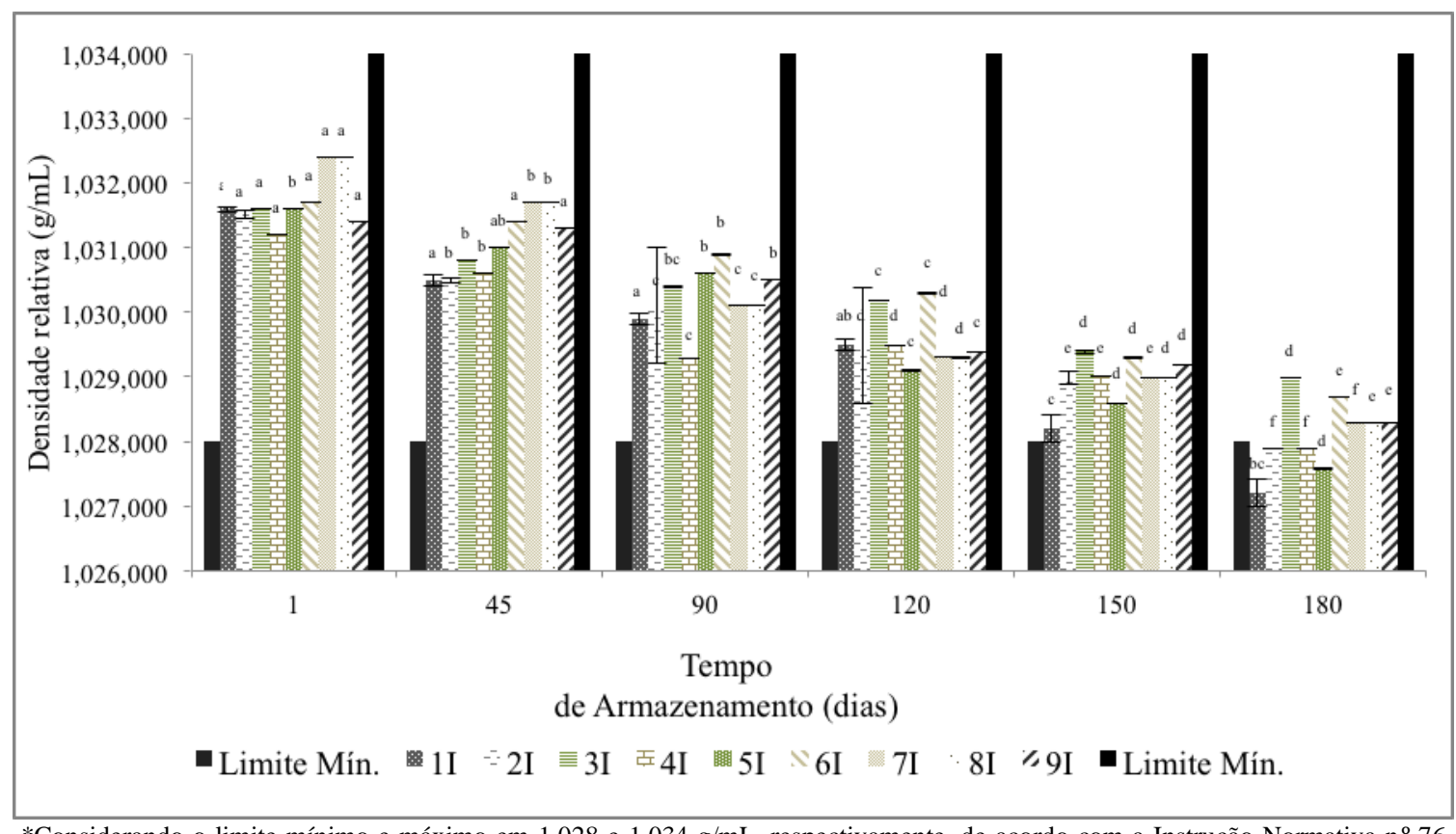

*Considerando o limite mínimo e máximo em 1,028 e 1,034 g/mL, respectivamente, de acordo com a Instrução Normativa ${ }^{\circ} 76$ (Brasil, 2018). Cada barra, no intervalo do tempo de armazenamento, está distribuída ordenadamente entre limite mínimo - marca $1 \mathrm{I}$ à marca $9 \mathrm{I}$ - limite máximo.

Fonte: Autores (2021).

Figura 6 - Densidade a $15^{\circ} \mathrm{C}$ para leite UHT desnatado*

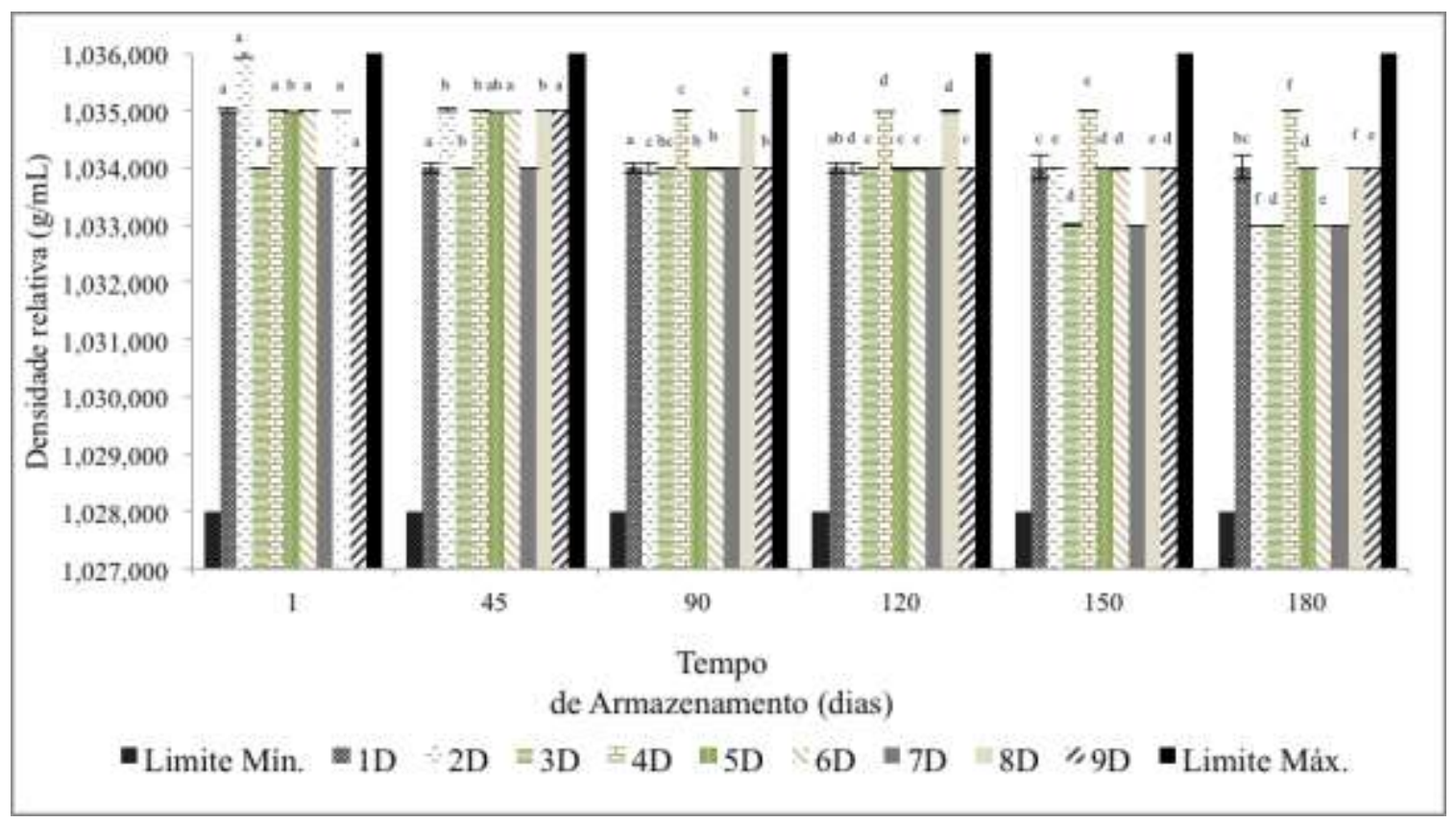

*Considerando o limite mínimo e máximo em 1,028 e 1,036 g/mL respectivamente, de acordo com a Instrução Normativa ${ }^{\circ} 76$ (Brasil, 2018). Cada barra, no intervalo do tempo de armazenamento, está distribuída ordenadamente entre limite mínimo - marca 1D à marca 9D - limite máximo.

Fonte: Autores (2021).

Foi verificado que quatro marcas de leite UHT integral (Figura 5) apresentaram resultados abaixo do padrão da legislação para o leite cru refrigerado (Brasil, 2018), sendo que para o leite UHT não há padrão na legislação vigente. No dia 180 foi observado um aumento de gordura separada no produto, depositada na parte superior da embalagem de todas as marcas de leite UHT integral, porém, em diferentes concentrações. 
As marcas de leite UHT desnatado apresentaram densidade dentro do que preconiza a legislação vigente (Brasil, 2018).

Soares et al. (2007) que avaliaram 10 amostras de leite UHT, e Arruda et al. (2007), que avaliaram 5 marcas de leite UHT integral, durante o prazo de validade, verificaram duas amostras com valores acima dos de referência (Brasil, 2018).

\subsection{Teor de gordura $(\mathrm{g} / \mathbf{1 0 0 g})$}

Os resultados apresentados na (Figura 7) para teor de gordura de leite UHT integral mostram um decréscimo neste parâmetro ao longo dos 180 dias de armazenamento, comportamento similar $(\mathrm{p}<0,05)$ para todas as marcas de leite analisadas.

Os valores médios de teor de gordura nas amostras de leite UHT integral de 6 marcas decresceram já no dia 45 de estocagem, estando abaixo do limite mínimo preconizado pelo RTIQ do leite UHT ( $\leq 3,0 \%$ de gordura) Brasil, 2017).

Domareski et al. (2010), avaliando diferentes marcas de leite UHT integral, relatou que $100 \%$ das amostras do Brasil se encontravam dentro dos valores mínimos determinados pela legislação para teor de gordura. Da mesma forma, Robim (2011), Martins et al. (2008) e Souza et al. (2010) relataram que todas as amostras de leite UHT pesquisadas estavam dentro dos padrões estabelecidos pela legislação para a porcentagem de gordura. Bersot et al. (2010) analisaram 150 amostras de leite UHT integral de três marcas e $29 \%$ das amostras tiveram o teor de gordura abaixo de $3,0 \mathrm{~g} / 100 \mathrm{~g}$ do que preconiza a legislação.

Diversas teorias são relatadas na literatura para a redução da gordura durante o tempo de armazenamento do leite UHT. De acordo com Tronco (2008), este decréscimo nos triglicerídeos não se justifica pela ação de bactérias lipolíticas pois estas estruturas são inacessíveis às lipases em leite UHT, mas sim, pela lipólise devido à ação de enzimas termorresistentes ao processamento térmico. Costa et al. (2010) reportam que os teores de gordura verificados no dia zero do seu estudo, e posteriormente decrescentes ao longo do armazenamento, tenham sido causados pela deficiência na homogeneização nas indústrias ou por deficiências nesse processo, associados à diminuição de $\mathrm{pH}$ ao longo do período de estocagem.

Figura 7 - Teor de gordura $(\mathrm{g} / 100 \mathrm{~g})$ do leite UHT integral*

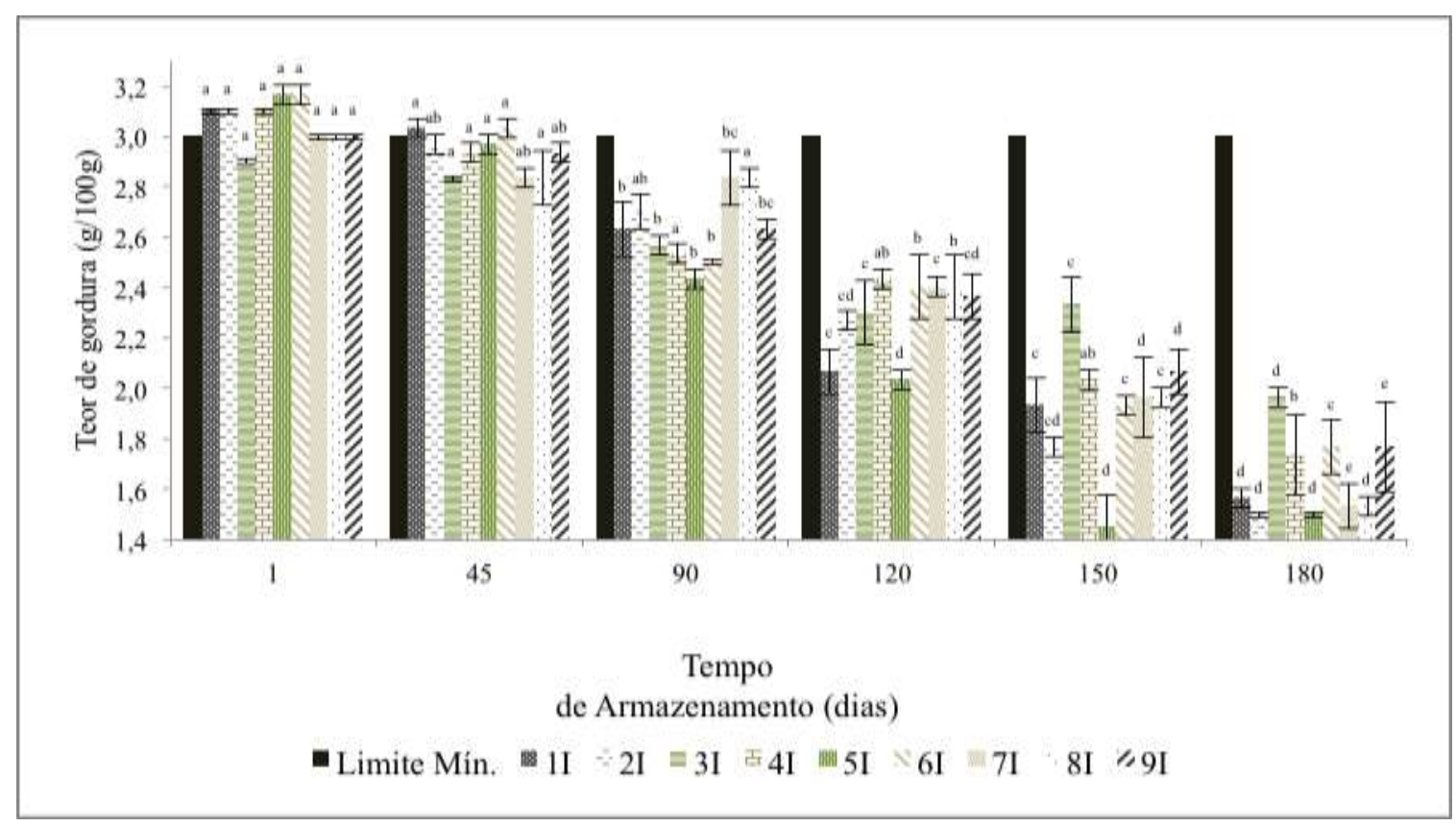

*Considerando seu limite mínimo em 3,0 g/100mL de acordo com o RTIQ do leite UHT (Brasil, 2017). Cada barra, no intervalo do tempo de armazenamento, está distribuída ordenadamente entre limite mínimo - marca 1I à marca 9I.

Fonte: Autores (2021). 
A legislação brasileira considera o produto sem gordura quando apresenta valores $\leq 0,5 \mathrm{~g} / \mathrm{L}$, portanto, todas as amostras de leite UHT desnatado estão nesta classificação (Brasil, 2017), pois, apresentaram teores abaixo do limite mínimo estipulado no dia 0 , decrescendo ao longo do tempo de armazenamento até que no dia 90, todas as amostras apresentaram teor $0,0 \mathrm{~g} / \mathrm{L}$ devido à segregação da gordura na parte superior da embalagem de leite.

\section{6 Índice Crioscópico $\left({ }^{\circ} \mathrm{H}\right)$}

Os resultados das análises de índice crioscópico (crioscopia) dos leites UHT integral e desnatado ao longo do tempo de estocagem mostram que o comportamento foi similar $(\mathrm{p}<0,05)$ entre todas as marcas de leite analisadas e decresceram durante os 180 dias de armazenamento (Figuras 8 e 9). Os valores de referência na legislação brasileira para o leite UHT são 0,530 a $-0.555^{\circ} \mathrm{H}$ (Brasil, 2017).

Duas amostras analisadas apresentaram índice crioscópico abaixo do padrão a partir do dia $90\left(-0,557^{\circ} \mathrm{H}\right.$ e $-0,558$ $\left.{ }^{\circ} \mathrm{H}\right)$, enquanto no dia 120, o total de marcas não conformes incluía mais três, totalizando cinco marcas fora do padrão da legislação brasileira. No último dia de ensaio, somente três marcas apresentaram-se em conformidade com a legislação. Uma das marcas apresentou índice crioscópico acima do padrão nas análises do dia 0 e 45, considerando-se, neste caso, a hipótese de uma fraude por aguagem, pois a adição de água no leite para aumentar o seu volume diminuiu os valores de crioscopia.

Figura 8 - Índice crioscópico das amostras de leite UHT integral*

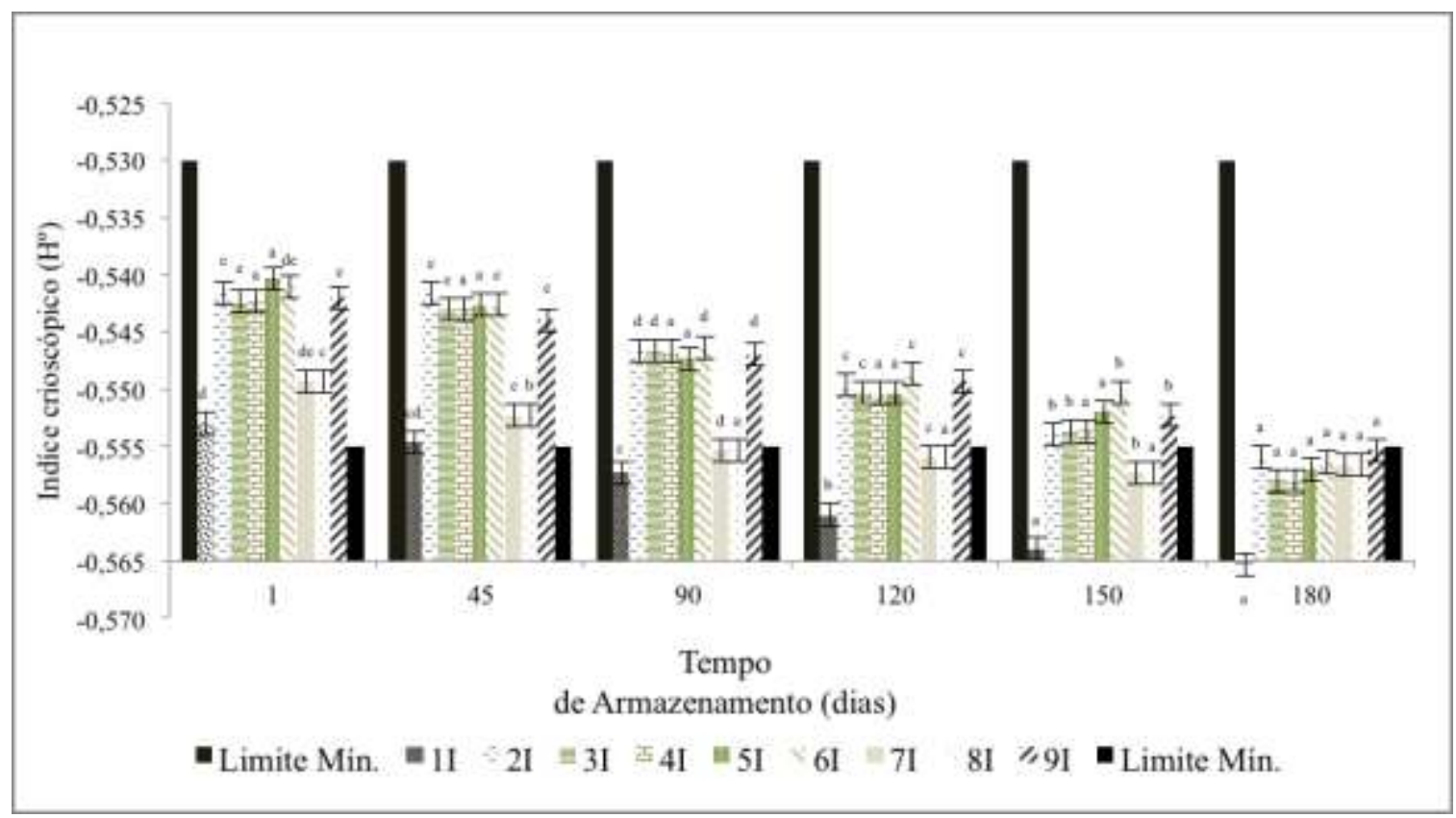

*Considerando os limites mínimo e máximo $\left(-0.530\right.$ e $-0.555^{\circ} \mathrm{H}$, respectivamente) de acordo com o Manual de Métodos Oficiais para Análise de Alimentos de Origem Animal (Brasil, 2017). Cada barra, no intervalo do tempo de armazenamento, está distribuída ordenadamente entre limite mínimo - marca 1I à marca 9I - limite máximo.

Fonte: Autores (2021). 
Figura 9 - Índice crioscópico das amostras de leite UHT desnatado*

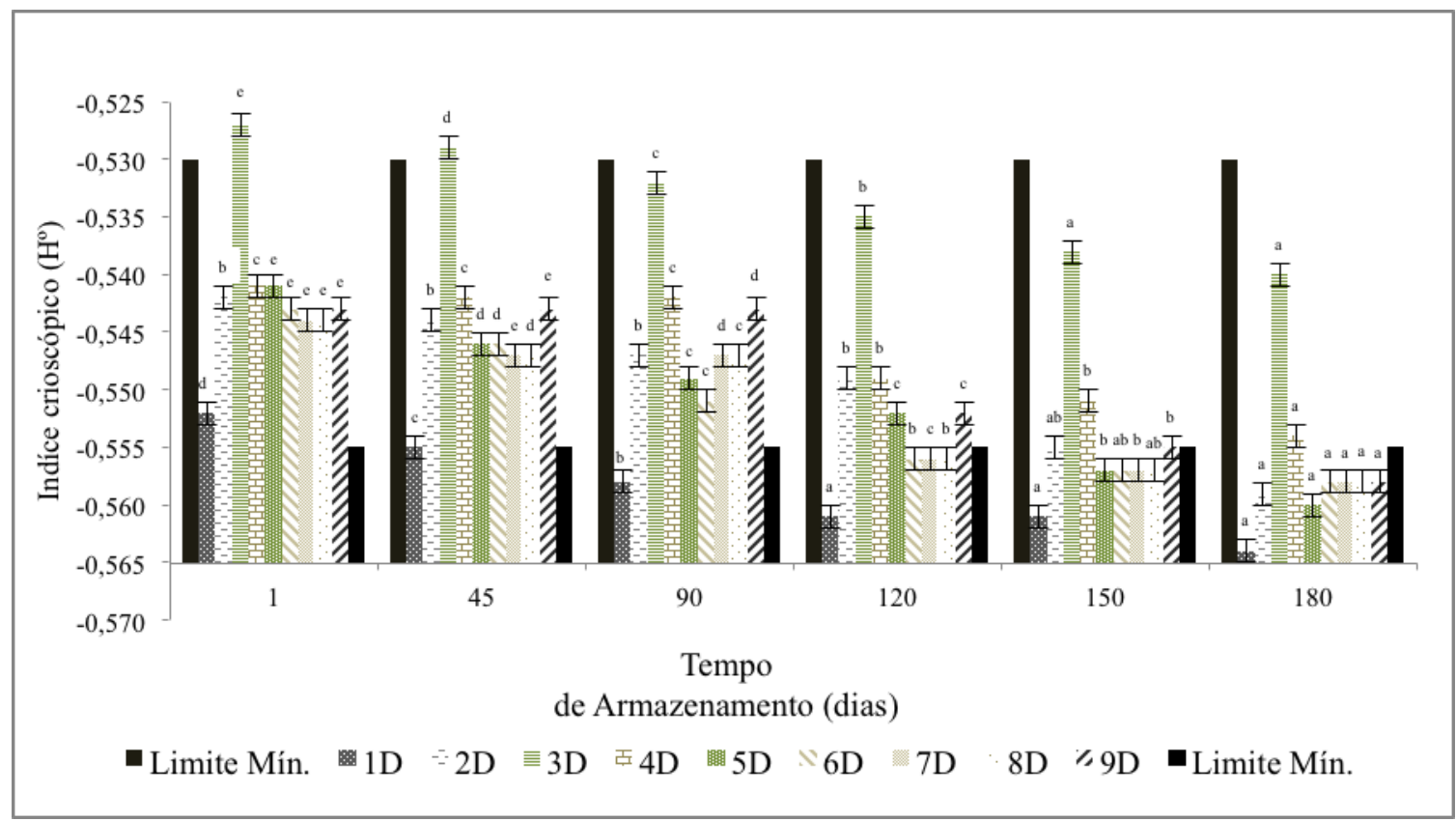

*Considerando os limites $\left(-0.530\right.$ e $-0.555^{\circ} \mathrm{H}$, respectivamente) de acordo com o Manual de Métodos Oficiais para Análise de Alimentos de Origem Animal (Brasil, 2017). Cada barra, no intervalo do tempo de armazenamento, está distribuída ordenadamente entre limite mínimo - marca 1D à marca 9D - limite máximo.

Fonte: Autores (2021).

\subsection{Extrato Seco Desengordurado (ESD) (g/100g)}

Os resultados para as análises de extrato seco desengordurado (ESD) pelo método Gravimétrico mostraram que o comportamento foi similar $(\mathrm{p}<0,05)$ para todas as marcas de leite analisadas, com valores decrescendo ao longo dos 180 dias de armazenamento (Figuras 10 e 11).

Figura 10 - Extrato seco desengordurado (ESD) em leite UHT integral analisado pelo método gravimétrico*

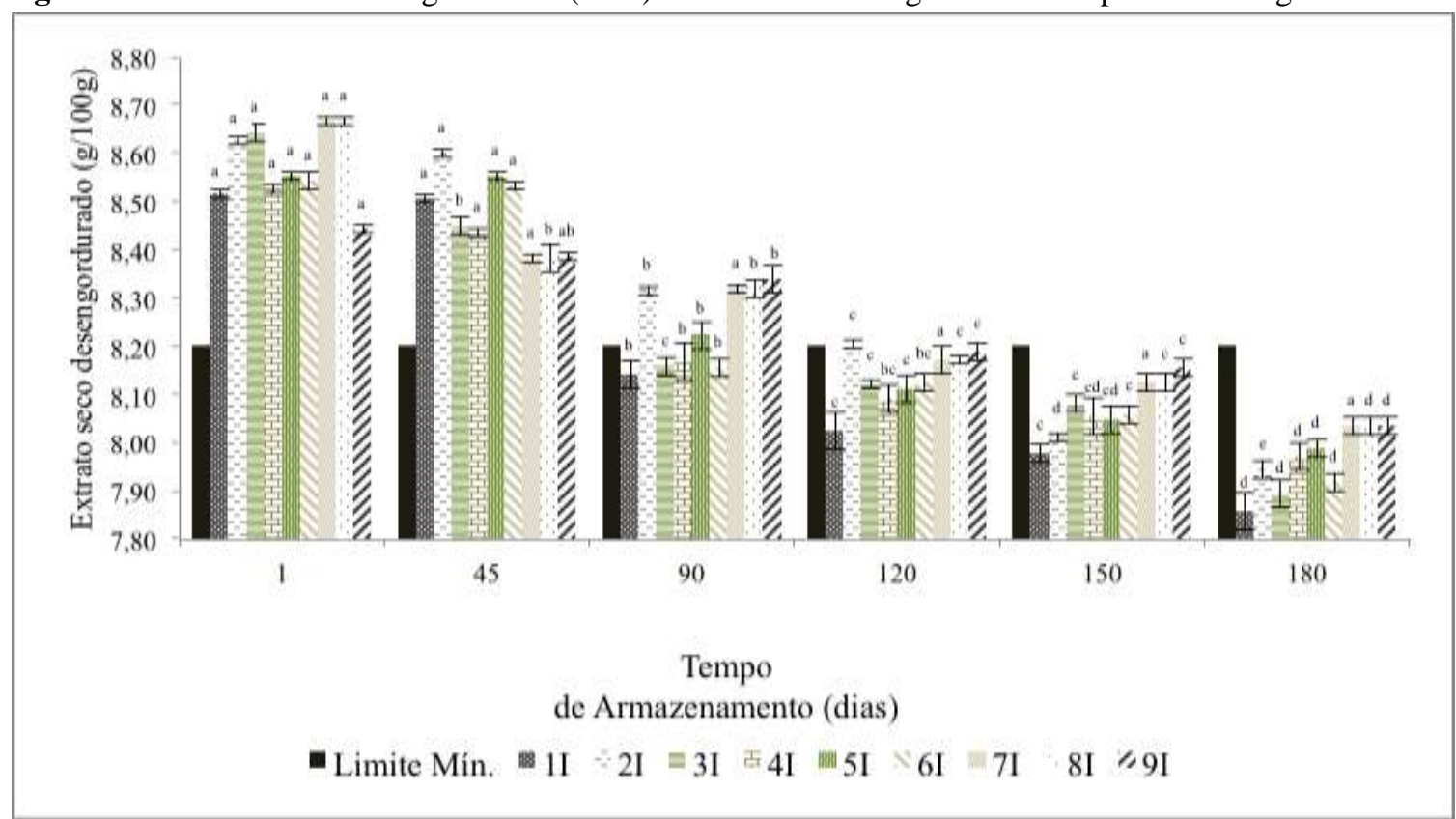

*Considerando o seu limite mínimo de 8,20 (g/100g) de acordo com o RTIQ do leite UHT (Brasil, 1997). Cada barra, no intervalo do tempo de armazenamento, está distribuída ordenadamente entre limite mínimo - marca 1I à marca 9I.

Fonte: Autores (2021). 
Figura 11 - Extrato seco desengordurado (ESD) em leite UHT desnatado analisado pelo método gravimétrico.

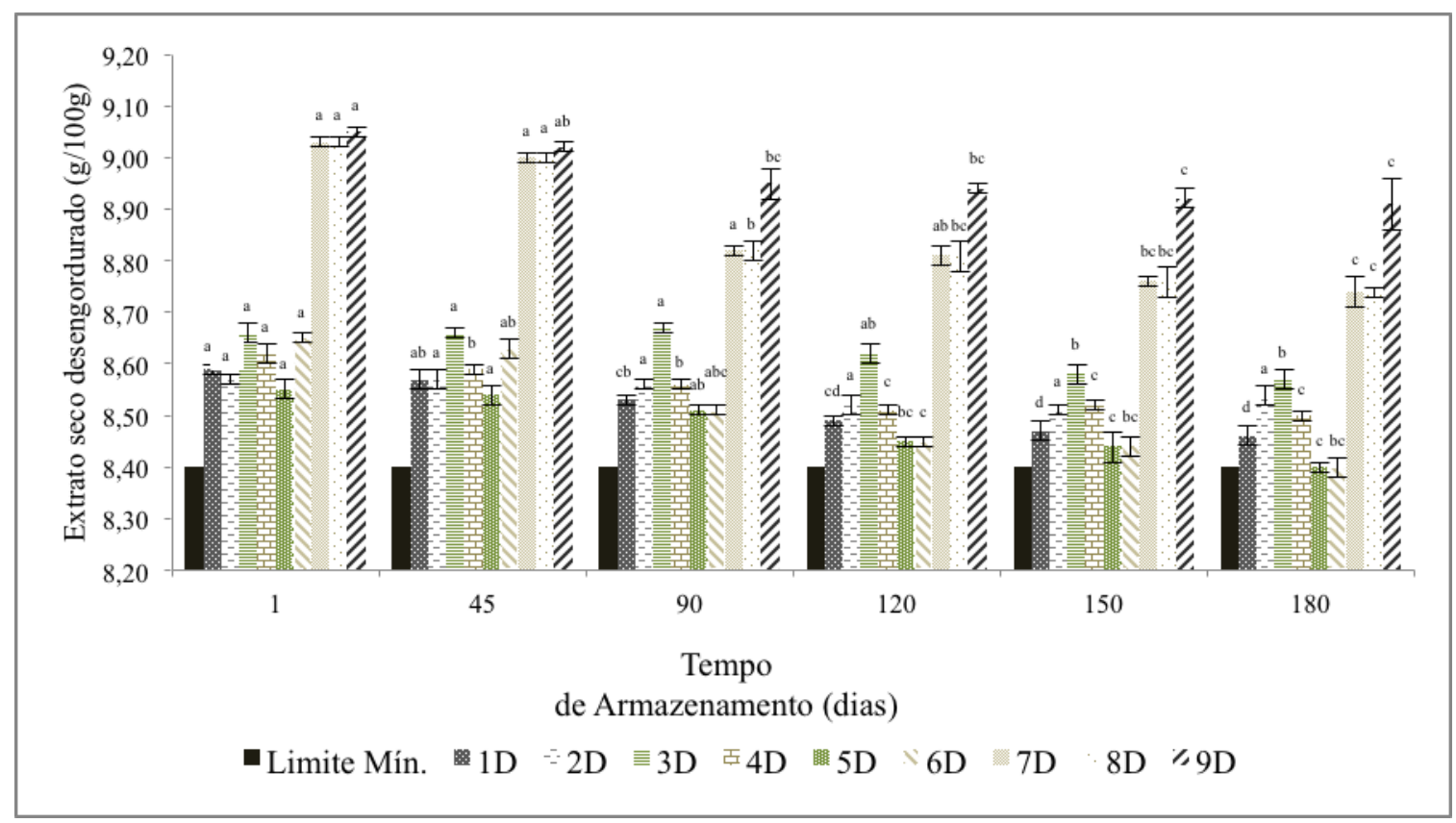

*Considerando o seu limite mínimo de 8,40 (g/100g) de acordo com o RTIQ do leite UHT (Brasil, 1997). Cada barra, no intervalo do tempo de armazenamento, está distribuída ordenadamente entre limite mínimo - marca 1D à marca 9D.

Fonte: Autores (2021).

O decréscimo para valores de ESD (método gravimétrico) nas amostras analisadas ocorre devido a separação de gordura encontrada no leite UHT, ou seja, a diminuição do teor de gordura do leite em conjunto com o extrato seco. Domaresk et al. (2010), analisou 4 marcas de leite UHT produzidos na América do Sul e verificou que todos os leites possuem ESD abaixo do padrão (Brasil, 1997), assim como os resultados apresentados no presente trabalho. Bersot et al. (2010) encontraram 50,7\% das amostras de leite comercializadas na cidade de Palotina-PR com ESD em desacordo com a legislação, estando abaixo de seu limite mínimo. Batista (2015), observou que o valor médio de ESD das amostras de leite UHT analisadas atenderam a legislação, porém, a amostra de leite UHT da última coleta realizada na estação do outono apresentou 7,85\% de ESD, tendo a relação com a diminuição da densidade do leite.

Segundo Real et al. (2013), um decréscimo na crioscopia pode ocorrer devido à lactose, a alguns minerais, a determinadas proteínas solúveis e aos gases dissolvidos (oxigênio, nitrogênio e dióxido de carbono). A lactose e os cloretos são os que mais afetam o ponto de congelamento.

O estabilizante citrato de sódio pode ter influência no resultado, uma vez que diminui o ponto de congelamento do leite. Beloti et al. (2010), Tamanini et al. (2011) e Seixas et al. (2014) observaram que a adição de 0,1\% de citrato de sódio, embora seja a quantidade máxima permitida pela legislação brasileira, provoca aprofundamento no ponto de congelamento do leite, alterando a crioscopia em até $-0,020{ }^{\circ} \mathrm{H}$, além de alterar a densidade (Brasil, 1997; Brasil, 2017). A adição deste estabilizante, além de colaborar para a diminuição deste parâmetro de qualidade, pode mascarar a ocorrência de fraudes, por conta da inserção de água ao longo do processamento térmico, fazendo com que os valores se aproximem de zero.

\section{Conclusão}

As análises físico-químicas demonstraram que, a maioria das amostras de leite, estavam dentro dos padrões estabelecidos pela legislação brasileira nos primeiros dias dos ensaios, exceto uma das marcas que apresentou expressiva não conformidade na análise de crioscopia de sua versão desnatada. O leite tipo integral desta mesma marca, apresentou valores de gordura e acidez abaixo do que preconiza a legislação brasileira na mesma data de análise. Estes resultados podem indicar que 
o leite foi fraudado por aguagem.

Todas as marcas ao longo do tempo de armazenamento apresentaram diversas falhas quando confrontadas com a legislação vigente em parâmetros como acidez, crioscopia, estabilidade, densidade, teor de gordura, ESD e pH, demonstrando que o processo precisa ser aperfeiçoado e monitorado, bem como, a matéria prima.

Todos os leites UHT analisados apresentaram não conformidades no último dia de sua validade, independente do ponto de partida. Com base neste estudo, verifica-se que as empresas e os órgãos regulamentadores brasileiros deveriam discutir quanto aos parâmetros de regulamentação dos prazos de validade.

\section{Referências}

Al-Saadi, J. M. S., \& Deeth, H. C. (2008). Cross-linking of proteins and other changes in UHT milk during storage at different temperatures. Aut. J. Dairy Technol, 63 (3), 93-99.

Andrioli, A. S., Furtado, M. A. M., Vilela, M. A. P., \& Meurer, V. M. (2001). Padrões físico-químicos de identidade do leite "longa vida" (UHT) comercializado na cidade de Juiz de Fora (MG). Revista do Instituto de Laticínios Candido Tostes, 56 (321), 50-54.

Arruda, P. M., Cruz A. G., Zoellner, S. S., Silva, R., Soares, M. M., Fernades, V. S., \& Galvão A. P. G. L. K. (2007). Características físico-químicas do leite pasteurizado tipo C e leite Ultra Alta Temperatura comercializados na cidade do Rio de Janeiro. Revista do Instituto Adolfo Lutz, 66 (2), $125-129$.

Batista, C. S. (2015). Estudo de correlação entre a qualidade do leite cru refrigerado e do leite UHT integral. 46 p. Dissertação (Mestrado profissional em Ciência e Tecnologia de Alimentos) - Instituto Federal do Sudeste de Minas Gerais, Belo Horizonte, MG.

Beloti, V., Mantovani, D., Silva, M. R., Tamanini, R., Garcia, D. T., \& Silva, F. A. (2010). Alterações do ponto de congelamento do leite por adição do estabilizante citrato de sódio. In Anais do IV Congresso Brasileiro de Qualidade do Leite, Florianópolis, SC.

Bersot, L. S., Galvão, J. A., Raymundo, N. K. L., Barcellos, V. C., Pinto, J. P. A. N., \& Maziero, M. T. (2010). Avaliação microbiológica e físico-química de leites UHT produzidos no Estado do Paraná - Brasil. Ciências Agrárias, 31 (3), 645-652.

Bhemer, M. L. A. (1999). Tecnologia do leite: produção, industrialização e análise. Nobel.

Brasil. (1984). Ministério da Agricultura e da Saúde. Resolução CISA/MA/MS n $n^{\circ} 10$, de 31 de julho de 1984. Dispõe sobre instruções para conservação nas fases de transporte, comercialização e consumo dos alimentos perecíveis, industrializados ou beneficiados, acondicionados em embalagens. http://www.cidasc.sc.gov.br/inspecao/files/2018/06/Anvisa-Legisla\%C3\%A7\%C3\%A3o-Resolu\%C3\%A7\%C3\%B5es.pdf

Brasil. (1997). Ministério da Agricultura, Pecuária e Abastecimento. Fixação de Identidade e Qualidade do Leite UHT (UAT): aprovado pela Portaria n 370 , de 04 de setembro de 1997. http://extranet.agricultura.gov.br/sislegisconsulta/consultarLegislacao.do?operacao=visualizr\&id=1252

Brasil. (2006). Ministério da Agricultura, Pecuária e abastecimento. Instrução Normativa $n^{o} 68$, de 12 de dezembro de 2006. http://www3.servicos.ms.gov.br/iagro_ged/pdf/958_ged.pdf

Brasil. (2017). Ministério da Agricultura, Pecuária e Abastecimento. Decreto $n^{\circ}$ 9.013, de 29 de março de 2017. Regulamenta a Lei nº 1.283 , de 18 de dezembro de 1950 , e a Lei $\mathrm{n}^{\mathrm{o}} 7.889$, de 23 de novembro de 1989 , que dispõem sobre a inspeção industrial e sanitária de produto s de origem animal. http://www.planalto.gov.br/ccivil_03/_ato2015-2018/2017/decreto/d9013.htm

Brasil. (2018). Ministério da Agricultura Pecuária e Abastecimento. Instrução Normativa nº 76, de novembro de 2018. https://www.gov.br/agricultura/pt-br

Brasil. (2019). Ministério da Agricultura, Pecuária e Abastecimento. Manual de Métodos Oficias para Análise de Alimentos de Origem Animal. https://www.gov.br/agricultura/pt-br/assuntos/laboratorios/credenciamento-e-laboratorios-credenciados/legislacao-metodos-credenciados/arquivos-metodosda-area-poa-iqa/ManualdeMtodosOficiaisparaAnlisedeAlimentosdeOrigemAnimal2ed.pdf

Brito, J. R. F., Furtado, M. A. M., Silva, P. H. F., \& Abreu, L. R. (2004). Variações regionais e sazionais na composição do leite. Revista do Instituto de Laticínios Cândido Tostes, 59, 24-31.

Bylund, G. (1995). Long life milk. In G. Bylund. Tetra Pak Dairy Processing Handbook (pp. 215-232). Lund: Tetra Pack Processing Systems AB.

Carvalho, B. M. A., Carvalho, L. M., Alcântra, L. A. P., \& Bonomo, R. C. F. (2007). Método de detecção de fraude em leite por adição de soro de queijo. Revista Electrónica de Veterinária, 6(8), 1-7.

Codex Alimentarius. (2004). Codex General Standard for the labelling of prepackaged foods. http://www.fao.org/docrep/005/Y2770E/y2770e02.htm

Costa, A. M. C., Oliveira, M. B., \& Moura, C. J. (2010). Avaliação de características físico-químicas de leites UAT produzido no estado de Goiás ao longo da estocagem. In Anais do IV Congresso Brasileiro de Qualidade do Leite, Florianópolis, SC.

Domareski, J. L., Bandiera, N. S., Sato, R. T., Aragon-Alegro, L. C., \& Santana, E. H. W. (2010) Avaliação físico-química e microbiológica do leite UHT comercializado em três países do Mercosul (Brasil, Argentina e Paraguai). Archivos Latinoamericanos de Nutricion, 60 (3), $261-269$.

Katsuda, M. S., Dias, L. F., \& Souza, A. H. P. (2009). Caracterização físico-química do leite UHT comercializado no norte do Paraná. In Anais do $26^{o}$ Congresso Nacional de Laticínios, 26, Juiz de Fora, MG. 
Lewis, M., \& Heppel N. (2000). Continous termal processing of foods: Pasteurization and UHT sterilization. Aspen Publisher, $331-368$.

Luiz, D. J., Simões, B. N., Tamostu, S. R., Casale, A. A. L., \& Walter, S. E. H. (2010). Avaliação físico-química e microbiológica do leite UHT comercializado em três países do Mercosul (Brasil, Argentina e Paraguai). Archivos Latinoamericanos de Nutrición, 60(3), 261-269.

Martins, A. M. C. V., Rossi Junior, O. D., Salotti, B. M., Bürger, K. P., Cortez, A. L. L., \& Cardozo, M. V. (2008). Efeito do processamento UAT (Ultra Alta Temperatura) sobre as características físico-químicas do leite. Ciência Tecnologia de Alimentos, 28 (2), 295-298.

Oliveira, M. M. A. \& Nunes, I. F. (2003). Análise Microbiológico e físico-químico do leite pasteurizado "tipo C" comercializado em Teresina, PI. Revista Higiene Alimentar, 17 (111), 92-94.

Pereira A. S., Shitsuka, D. M., Parreira, F. J., \& Shitsuka, R. (2018). Metodologia da pesquisa científica. UFSM. https://repositorio.ufsm.br/bitstream/handle/1/15824/Lic_Computacao_Metodologia-Pesquisa-Cientifica.pdf?sequence=1

Pereira, P. C. (2014). Milk nutritional composition and its role in human health. Nutrition, 30(6), 619-627.

Prata, L. F. (2001). Fundamentos de ciência do leite. FUNEP.

Real, C. G. A., Alegro, L. C. A., Turate, M., Silva, L. C. C., Souza, C. H. B. \& Santana, E. H. W. (2013). Avaliação da qualidade físico-química e microbiológica de leite UHT integral e determinação da proteólise durante armazenamento. Revista do Instituto de Laticínios Cândido Tostes, 68(394), 5-10.

Robim, M. S. (2011). Avaliação de diferentes marcas de leite UAT comercializadas no Estado do Rio de Janeiro e o efeito da fraude por aguagem na fabricação, composição e análise sensorial de iogurte. 98 p. Dissertação (Mestrado em Higiene Veterinária e Processamento Tecnológico de Produtos de Origem Animal) - Universidade Federal Fluminense, Niterói, RJ.

Rodrigues, F. A., Santos, T. P., Araújo, E. G., Braga, K. M. S., \& Pimenta, V. S. C. (2016). Citometria de fluxo: histórico, princípios básicos e aplicações em pesquisa. Enciclopédia Biosfera, Centro Científico Conhecer, 13(23).

Seixas, F. N., Fagnani, R., Rios, E. A., Pereira, J. R., Tamanini, R., \& Beloti, V. (2014). Comparação de métodos para detecção de fosfatase alcalina e peroxidase em leite. Revista do Instituto de Laticínios Cândido Tostes, 69(1), 17-24. 10.14295/2238-6416.v69i1.302

Silva, P. H. F., Pereira, D. B. C., Oliveira, L. L., \& Costa Junior, L. C. G. (1997). Físico-química do leite e derivados: métodos analíticos. Juiz de Fora: Oficina da Impressão Gráfica e Editora Ltda.

Singh, H. (2004). Heat stability of milk. International Journal of Dairy Technology, 57, 111-119.

Soares, M. M., Arruda, P. M., Cruz, A. G., Zoellner, S. S., Silva, R. Fernandes, V. S., \& Galvão, A. P. G. L. K. (2007). Características físico-químicas do leite pasteurizado tipo C e leite ultra alta temperatura comercializados na cidade do Rio de Janeiro. Revista do Instituto Adolfo Lutz, 66(2), 126-129.

Souza, A. H. P., Katsuda, M. K., \& Dias L. F. (2010). Avaliação físico-química do leite UHT e pasteurizado comercializado na cidade de Londrina - PR. Revista Brasileira de Pesquisa em Alimentos, 1(1), 39-42.

Statsoft, Inc. (2004). STATISTICA (data analysis software system), version 7. http:www.statsoft.com

Tamanini, R., Beloti, V., Ribeiro Junior, J. C., Silva, L. C. C., Yamada, A. K., \& Silva, F. A. (2011). Contribuição ao estudo da qualidade microbiológica e físico-química do leite UHT. Revista do Instituto de Laticínios Cândido Tostes, 66(382), 27-33.

Tronco, V. M. (2003). Manual para inspeção da qualidade do leite. UFSM.

Tronco, V. M. (2008). Manual para a inspeção da qualidade do leite. UFSM.

Walstra, P., Wouters, J. T. M., \& Geurts, T. J. (2006). Dairy science and technology. CRC Press. 